\title{
M-Health Service for Train Passengers Using Mobile GPS System: An ArchiMate Service Layer Model
}

\author{
MUHAMMAD SAJID*, KAMRAN AHSAN*, AND MUHAMMAD SARIM* \\ RECEIVED ON 02.07.2015 ACCEPTED ON 14.12.2015 \\ ABSTRACT
}

\begin{abstract}
EA(Enterprise Architecture) is an instrument that is employed to describe the organization's structure, business layout and operations within the IT (Information Technology) environment. Different types of organizations extensively employed EA for aligning their business and operations with IT resources. EA may also be employed in non-organizational setting such as service providing agencies; rescue, medical emergency and education services. This paper suggests an EAF (Enterprise Architecture Framework) for non-organizational setting by critically analyzing the top four EAs. The paper also proposes a new m-Health service model based on the mobile GPS (Global Positioning System) for train/ rail passengers by employing the ArchiMate modeling language and compares the proposed model with existing service providers.
\end{abstract}

Key Words: Information System, Enterprise Architecture, Service Layer, Information Technology, Healthcare, Pakistan Railway.

\section{INTRODUCTION}

$\mathrm{E}$ A is a framework broadly used as a tool for describing the organization's structure, services and business operations. EA depicts the relation among different components of the organizations. The main objective of employing EA is to align the IT resources with organization services and business [1] as well as aligning the organization's goals and objectives within the IT. The alignment of IT with business and services reduce the overall costs of IT and provide faster and better solutions to certain service/business problems [25]. EA systematizes the logical flow between data, application and technology infrastructure that symbolizes organizational business practices [6].
EA is extensively employed in different business organizations, NGOs (Non-Government Organizations) and Government Organizations. EA can also be applied for service providing agencies (non-organizational settings); such as, delivering services to people of certain vicinity through technology including rescue and emergency services and educational services. These services are offered by government and non-government agencies. An enterprise architecture model may be helpful in designing, aligning and better understanding of these services.

EA is effectively employed in healthcare organizations and resolves the interoperability and integration problems

* Department of Computer Science, Federal Urdu University of Arts, Science \& Technology, Karachi.

Mehran University Research Journal of Engineering \& Technology, Volume 36, No. 1, January, 2017 [p-ISSN: 0254-7821, e-ISSN: 2413-7219] 
among electronic medical record systems of two or more healthcare organizations. Pakistan is also facing serious health problems due to the shortage of doctors. Reliable health care services are only available in big cities. No medical health care services are available in remote areas of Pakistan, especially during travelling by trains. Hundreds of passengers are affected from medical emergencies due to non-availability of proper medical services in trains. In this connection this research proposes a better m-Health service model based on ArchiMate service layer. It also suggests a better EAF for modeling, designing, aligning and understanding different functions of the service providing agency.

This research is divided into three sections. The first section briefly defines top four EAFs with their deficiencies and suggests a better EA for nonorganizational setting. Second section explains a new $\mathrm{m}$ health ArchiMate model for train passengers and finally the last section discusses the proposed model and includes the results of an initial assessment.

\section{ENTERPRISE ARCHITECTURE FRAMEWORK}

The EA framework addresses the IT/IS and business/ service requirements of an organization. It describes how to design and practice EA within an information system. An EAF offers an environment for hardware, software and network to work cooperatively [7].

Temporarily numerous EAFs are used in different organizations. Many of the frameworks address similar views. Similarly, some frameworks address particular needs and many are general in nature. The top four EAF are briefly stated below.

\subsubsection{Zachman Framework}

The Zachman Framework is introduced by Zachman [8]. This framework is concerned with IT/IS and usually depict as a $6 \times 6$ matrix as shown in Fig. 1. The rows show the perspective and columns represent the six basic questions in the scenario of perspective [9]. Zachman framework focuses on designing documents, details, and models of organization within IS. In other words "Zachman Framework" is a taxonomy for organizing architectural fragments. Due to the absence of step by step process it is extremely difficult to create new architecture in Zachman Framework [10].

\subsection{Federal Enterprise Architecture Framework}

FEAF (Federal Enterprise Architecture Framework) is developed by employing the classification of five

\begin{tabular}{|c|c|c|c|c|c|c|}
\hline & $\begin{array}{c}\text { What } \\
\text { Data }\end{array}$ & $\begin{array}{c}\text { How } \\
\text { Function }\end{array}$ & $\begin{array}{c}\text { Where } \\
\text { Locations }\end{array}$ & $\begin{array}{c}\text { Who } \\
\text { People }\end{array}$ & $\begin{array}{c}\text { When } \\
\text { Time }\end{array}$ & $\begin{array}{c}\text { Why } \\
\text { Motivation }\end{array}$ \\
\hline Scope Planner & & & & & & \\
\hline $\begin{array}{c}\text { Business Model } \\
\text { Business Owner }\end{array}$ & & & & & & \\
\hline $\begin{array}{c}\text { System Model } \\
\text { Designer }\end{array}$ & & & & & & \\
\hline $\begin{array}{c}\text { Technology } \\
\text { Model } \\
\text { Implementer }\end{array}$ & & & & & & \\
\hline $\begin{array}{c}\text { Detailed } \\
\text { Representation } \\
\text { Subcontractor }\end{array}$ & & & & & & \\
\hline $\begin{array}{c}\text { Functional } \\
\text { Areas System }\end{array}$ & & & & & & \\
\hline
\end{tabular}

FIG.1. ZACHMAN 6X6 MATRIX

Mehran University Research Journal of Engineering \& Technology, Volume 36, No. 1, January, 2017 [p-ISSN: 0254-7821, e-ISSN: 2413-7219] 
reference models including PRM (Performance Reference Model), BRM (Business Reference Model), SRM (Service component Reference Model), DRM (Data Reference Model) and TRM (Technical Reference Model) as shown in Fig. 2. This framework facilitates US Federal Agencies to share information and design common process between other agencies. The FEAF also focuses on functional roles and core team member's responsibilities [11]. FEAF is only used in the government domain of the united states and is limited due to the lack of a roadmap, methodology and automatic model transformation.

\subsection{Treasury Enterprise Architecture Framework}

TEAF (Treasury Enterprise Architecture Framework) deals with treasury related activities. The intention of TEAF is to provide assistance in developing and redesigning business methods. TEAF also fulfill, the requirements of modern legislation, information sharing, and depicts the general requirements of the organization [12]. TEAF addresses four basic activties: EA strategy, EA management process, EA approach, and the development of an EA repository. Weakness of the TEAF is only restricted to treasury domain.

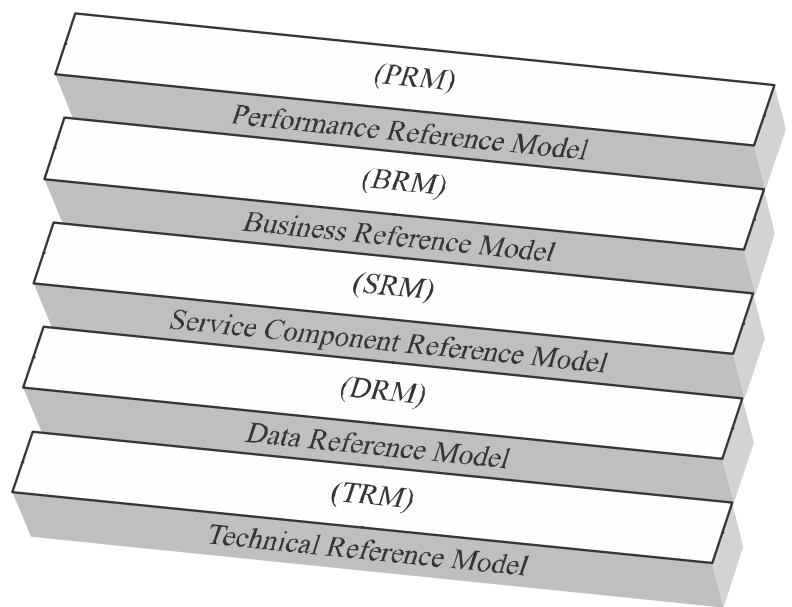

FIG. 2. FEAF REFERENCES MODELS

\subsection{The Open Group Architecture Framework and ArchiMate}

The TOGAF (The Open Group Architecture Framework) is introduced in 1995. It is an Open Group standard and based on "US Defense Department Technical Architecture Framework". TOGAF is a universal framework that motivates any type of organizations to employ TOGAF freely for designing EA. TOGAF enables the organization to assess and construct the right architecture. TOGAF splits the enterprise architecture in four levels: Business Architecture, Data Architecture, Application Architecture and Technical Architecture. ADM (Architecture Development Method) and ACM (Architecture Content Framework) are the essence of TOGAF [13-14].

The ArchiMate framework is another Open Group standard and addresses lifecycle of TOGAF and deals with three phases B, C and D as shown in Fig. 3. It offers standard graphical language for explaining the enterprise architecture model.

ArchiMate is divided in two parts, first is "Aspect" (three columns) and second is "Layer" (three rows) [15]. The rows represent as the layers (application layer, technology layer and business/service layer) and columns are symbolized as aspects (passive structure or information aspects, behavior aspect and active structure or structure aspect)) as shown in Fig. 4.

These aspects may be interpreted in natural language as shown in Fig. 5. Information aspect deals with events, data objects, information objects as well as physical objects. The behavior aspect [17] focuses on unit of activities such as services, procedures and functions. These activities are performed by active structural elements. Structure aspect addresses those entities which can show the behavior. For instance, business actors, application components and devices. 
Judicious review of top four EAF shows that the Zachman EFA lacks the step- by- step process and includes heavy taxonomy. FEAF is limited to US government domain and lacks the roadmap, whereas Treasury EAF only addresses Treasury matters. Usually simple and understandable EAF is more effective in a non-organizational environment and may feed several stakeholders collectively and TOGAF/ArchiMate is one of them due to its generalization, simplicity and communicative power. The next section of this paper demonstrates how to use ArchiMate in non-organization sittings by proposing new $\mathrm{m}$-Health service model based on GPS system for Pakistan railway passengers.
Pakistan railway moved $47,689,944$ passengers during the year 2013-2014 by running 30,583 passenger trains over the year [18]. There are roughly 558 railway stations in

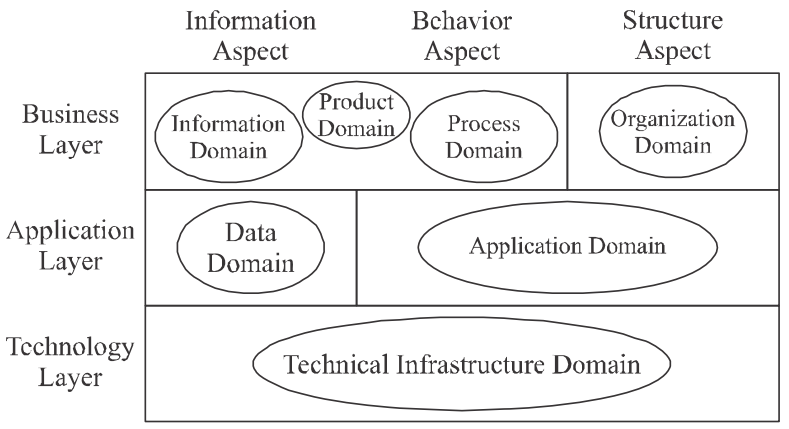

FIG. 4. ARCHIMATE FRAMEWORK [16]

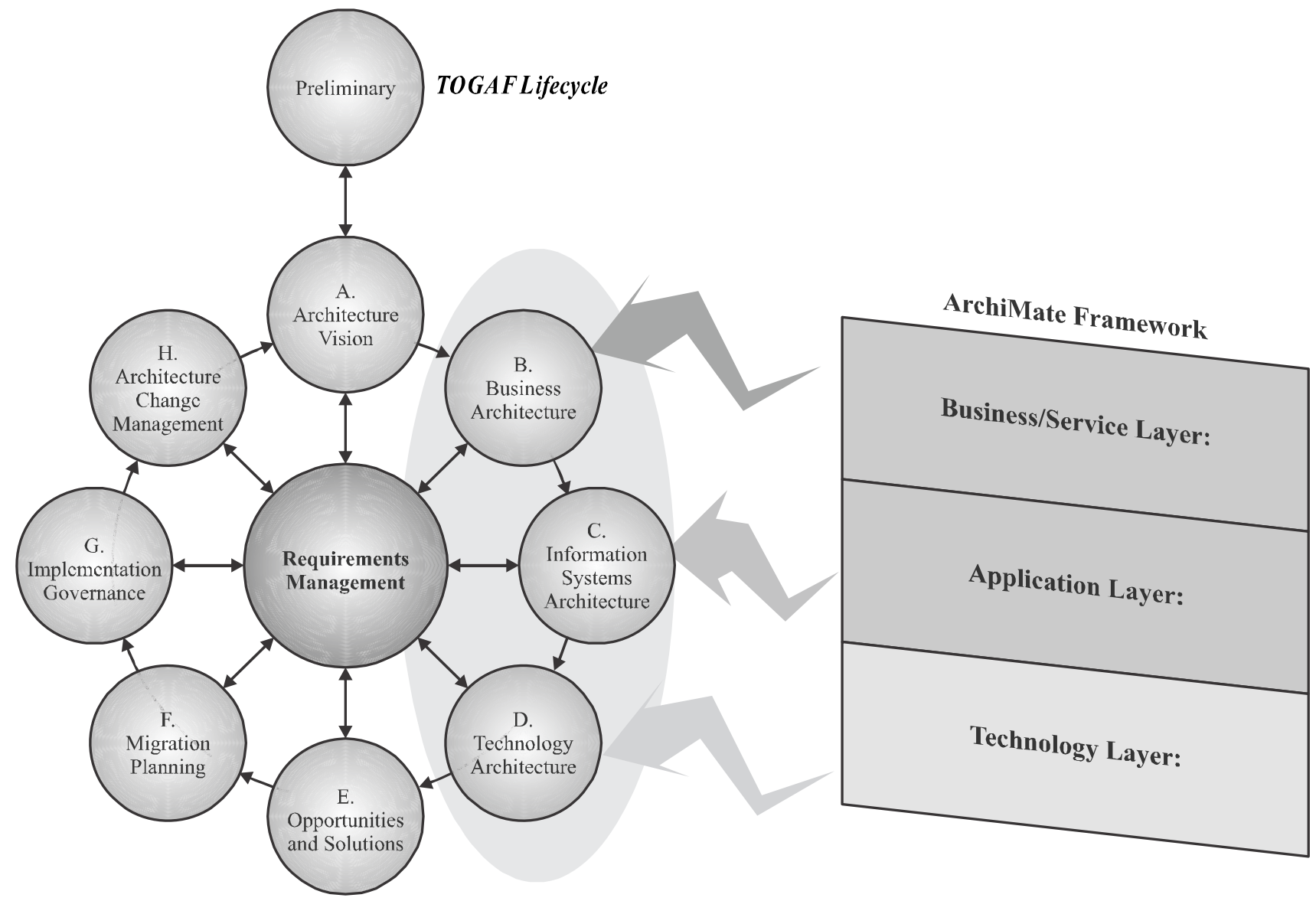

FIG. 3. TOGAF LIFECYCLE AND ARCHIMATE

Mehran University Research Journal of Engineering \& Technology, Volume 36, No. 1, January, 2017 [p-ISSN: 0254-7821, e-ISSN: 2413-7219] 
Pakistan [19] and health care services are available only on big stations [20]. According to Pakistan railways the Guard "In-charge of the train" is responsible of First Aid Boxes and serious medical cases are referred to Railway Hospitals at big stations [20]. The fact is that hundreds of passengers are affected from medical emergencies during traveling due to non-availability of proper medical services in trains. In this case mobile technology may play an important role to dissolve this situation and provide health services during traveling by trains. Approximately $60 \%$ people own their mobile sets in Pakistan and this number is increasing rapidly. Around 31405 mobile towers [21] are serving mobile phone services in urban and rural areas of Pakistan. By considering all these facts this research proposes an ArchiMate model of mobile based healthcare service. This model depicts all the components of mobile based health services. In other words, this model provides CT scan view of mobile based health service by depicting service functionality, aligning services with application and technology. This CT scan view assists to develop and deploy this health care service.

\section{ARCHIMATE SERVICE LAYER MODEL OF M-HEALTH USING GPS SYSTEM}

This model is divided into two levels service, namely 1 and 2. Each level is divided into three aspects: information aspects, behavior aspect and the structure aspect as shown in Fig. 6.

\subsection{Level-1}

The first level of proposed model provides health service remotely through mobile phone and tracks the patient, doctor and ambulance location through the GPS system as shown in Fig. 7.

Structure aspect of level 1 contains two elements, actor (patient) and roles ( $m$-health service). The information aspect holds the information object elements (medical prescription) and event (healthcare service request). Whereas the behavior aspect includes functions (patient tracking function, symptoms collection function, symptoms analysis function, ambulance/doctor tracking function) and processes location tracking service through GPS, symptoms collection service, diagnosis service.

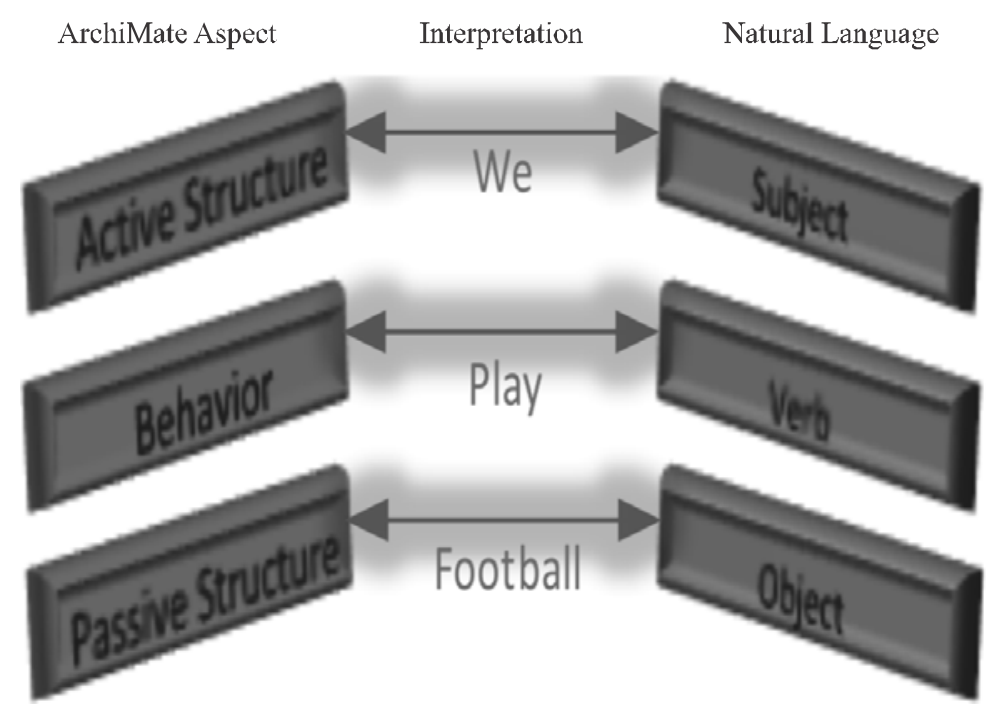

FIG. 5. ARCHIMATE ASPECTS INTERPRETATION IN NATURAL LANGUAGE

Mehran University Research Journal of Engineering \& Technology, Volume 36, No. 1, January, 2017 [p-ISSN: 0254-7821, e-ISSN: 2413-7219] 
The actor of an active structure initiates service through the mobile phone app. This service is started by firing the event (request health service) that is a part of both passive and behavior aspect. The first step of behavior aspect is patient tracking function which is triggered by event object. This function starts GPS tracking service on user/ patient mobile and collects GPS coordinates in the form of latitude and longitude and sends to healthcare call center and later stores in the database of information system. Second step (symptoms collection function) is invoked by the first step. In this service the medical problems are collected through telephonic conversation by the paramedical staff or doctor. The third step is to analyze the collected medical problems or symptoms by triggering the symptoms analysis function. The third function starts the symptom analysis services and prepares the medical advice in the form of medical prescription by the doctors or paramedical staff. All these functions will be carried out in the iterative manner. If illness is serious and patient needs physical examination or requires hospitalization then doctor/ambulance tracking function is invoked by the step 3 . This function collects the location of doctors, paramedical staff and ambulance location which are registered in healthcare call center by using the call center app on their mobile. This location is gathered by mobile phone GPS system and stores in call center information systems database.

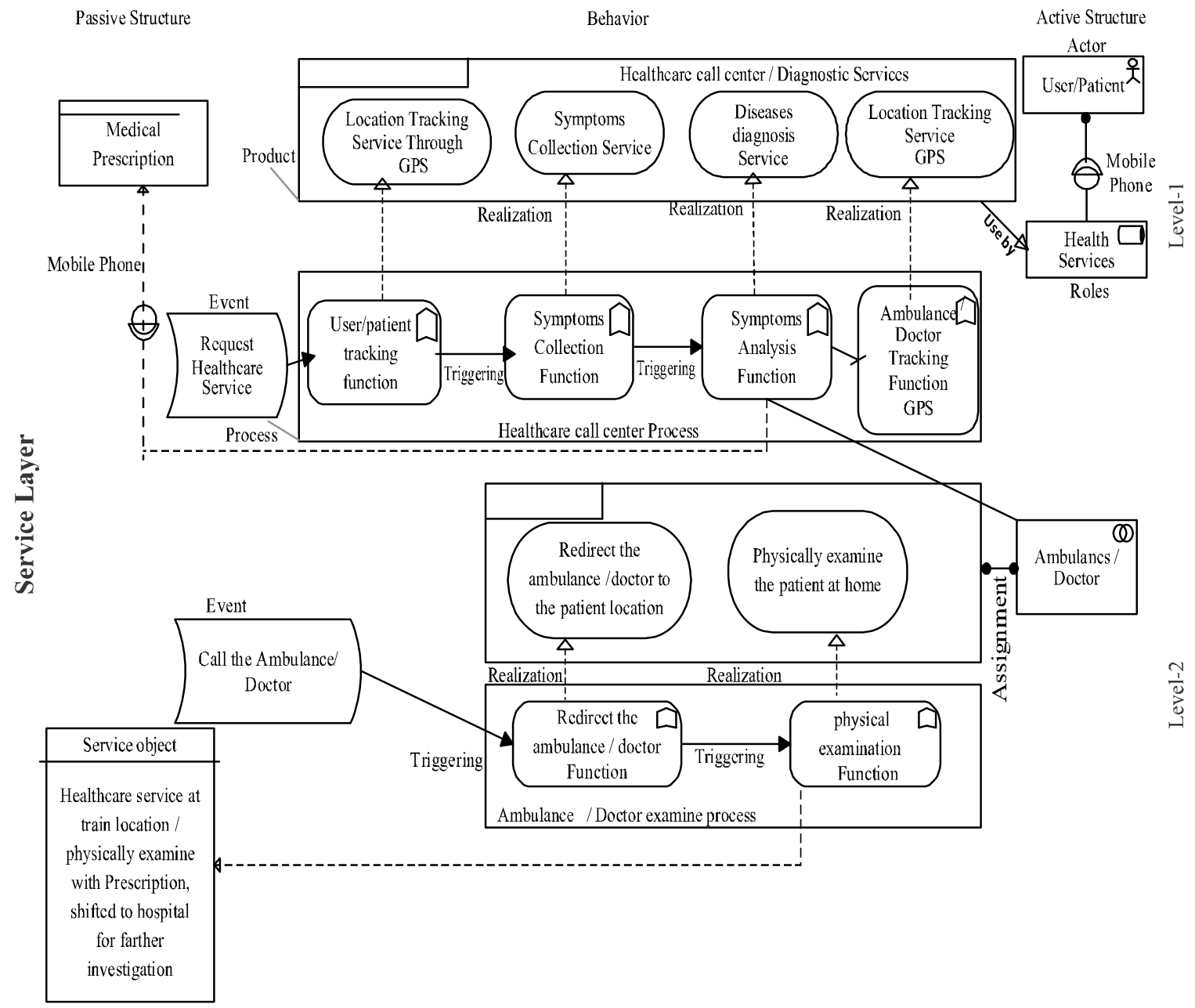

FIG. 6. SERVICE LAYER MODEL OF M-HEALTH USING GPS SYSTEM

Mehran University Research Journal of Engineering \& Technology, Volume 36, No. 1, January, 2017 [p-ISSN: 0254-7821, e-ISSN: 2413-7219] 


\subsection{Level-2}

The level-2 of proposed model explains how to find nearest doctor/ambulance and redirect them to patient location. The structure aspect holds one collaboration element (doctor/ambulance). The passive structure contains a service object (Healthcare service at train location/physically examines, shifts to hospital for further investigation) and behavior structure includes functions (redirect the ambulance/doctor function and physical examination function) as shown in Fig. 8.
The level 2 services are started when a call center agent triggers the event (call ambulance/doctor). This event element activates the function (redirect the ambulance/ doctor function) by calling to redirect the ambulance/ doctor to the patient location through a service. This service gathers the patient and doctor/ambulance location from call center information system. It also identifies the nearest doctor or ambulance from the patient or train and redirects the doctor or ambulance to the patient for physical examination or shifting the patient to hospital. Finally, the physical examination function will be executed.

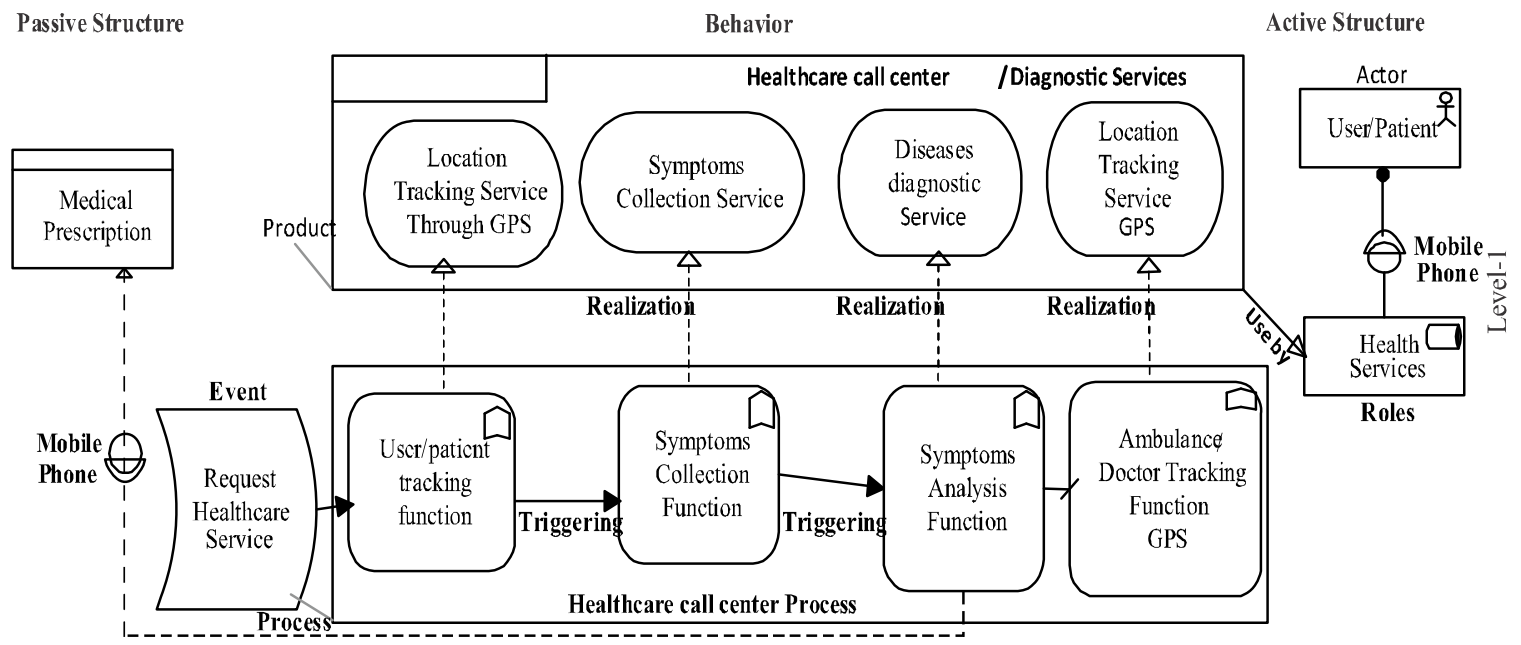

FIG. 7. PROPOSED ARCHIMATE M-HEALTH SERVICE LAYER MODEL LEVEL-1

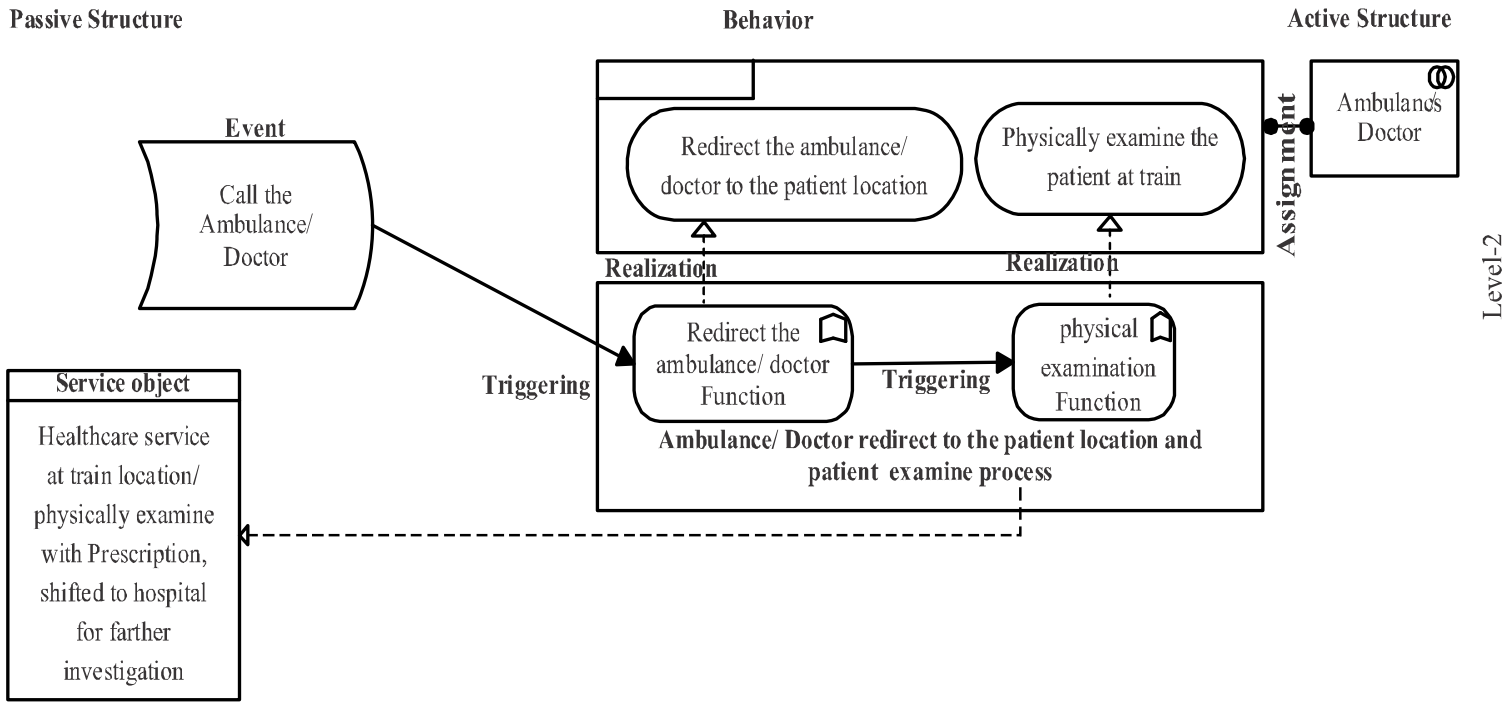

FIG. 8. PROPOSED ARCHIMATE M-HEALTH SERVICE LAYER MODEL LEVEL-2

Mehran University Research Journal of Engineering \& Technology, Volume 36, No. 1, January, 2017 [p-ISSN: 0254-7821, e-ISSN: 2413-7219] 
This function runs the service which physically examines the patient at the train by a doctor. After patient examination doctor decides wether patient needs hospitalization or medical prescription in the form of service object that is a part of passive structure.

\section{RESULTS AND DISCUSSION}

The proposed ArchiMate service layer model is most effective for train passengers in a medical emergency situation as compared to existing medical emergency services such as Rescue 1122, Aman ambulance and Tele Health service, Chhipa and Edhi ambulance service. The comparison of a proposed model and existing services is shown in Fig. 9. This comparison is performed on the basis of five questions which were asked from four well known emergency service providers. Table 1 shows these questions.

This research evaluates the five most popular services on five parameters and the results of evaluations are as under.

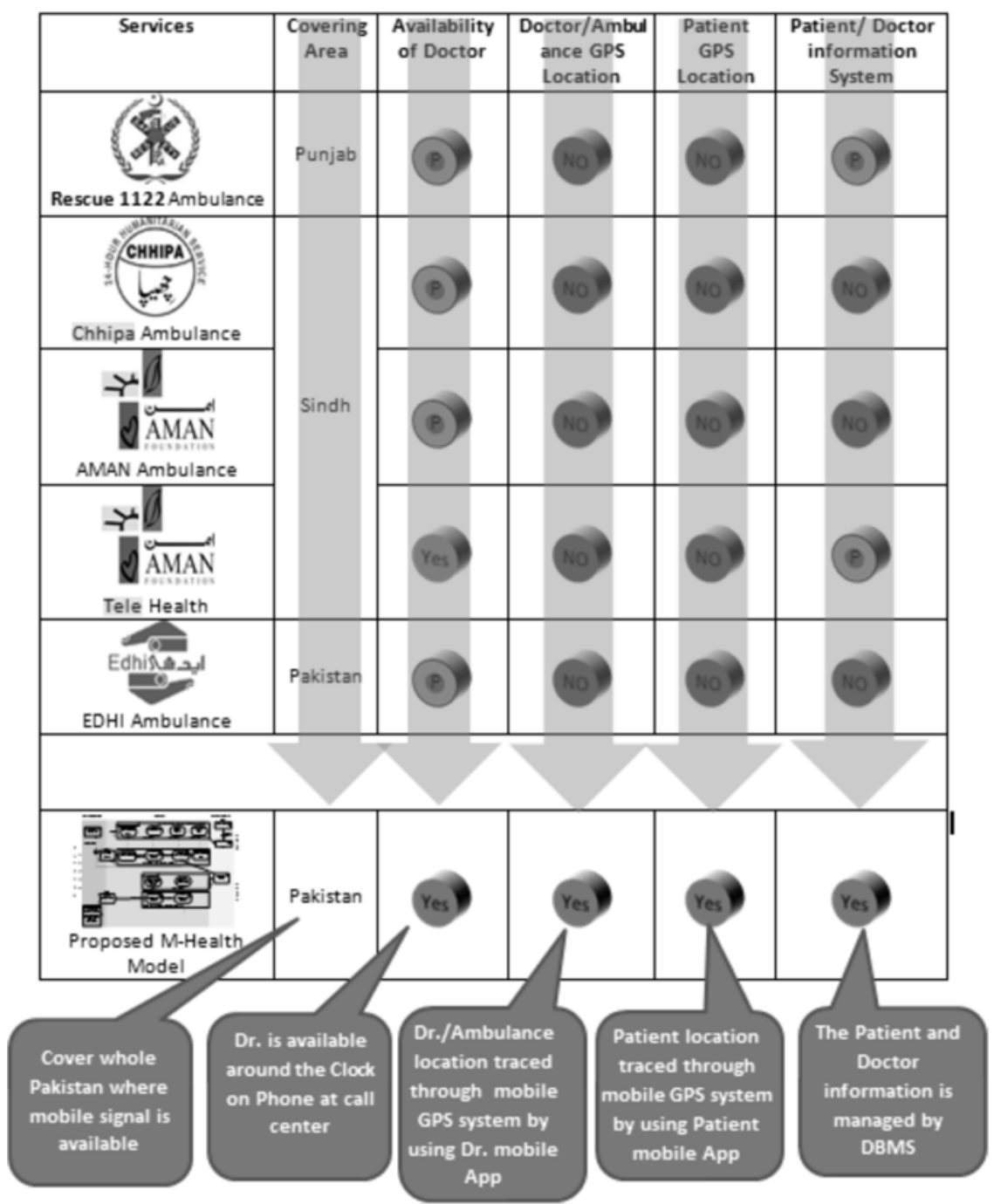

NO $=$ NOT AVAILABLE, YES=AVAILABLE, P=P ARTIALY AVAILABLE.

FIG. 9. COMPARISON OF EXISTING SERVICES AND THE PROPOSED MODEL 
Parameter-1 Covering Area: According to Fig. 9, one service is covering the big cities of Punjab, 3 cover Karachi and one is covers the whole Pakistan. On the other hand the proposed model covers the whole Pakistan, where the mobile signal is available. According to Pakistan economic survey report 2013-2014, the covered area of Pakistan land by mobile signal is $92 \%$ [22]. So the proposed model covers the $92 \%$ area of Pakistan.

Parameter-2 Availability of Doctor: The analysis shows that all existing services do not provide doctor all the time except the proposed one. The Doctor is available round the clock on the phone at the call center and accessible through mobile Applications.

\section{Parameter-3 Doctor/Ambulance Location Tracking}

System through GPS: None of any service provider has a location tracking system for their doctors or ambulance. The proposed research model can track doctor and ambulance locations through the GPS system by employing mobile app on the doctor's mobile device. The doctor with the mobile app can enable his GPS tracking and also permits to update his/her availability status.

Parameter-4 Patient Location Tracking: Neither of any existing service provider has a system to track patient location through mobile phone GPS system. The proposed model can track patient location through mobile app "Patient emergency call system".

TABLE 1. QUESTIONS

\begin{tabular}{|c|c|}
\hline No. & Questions \\
\hline 1. & How much areas does it cover \\
\hline 2. & Are doctors available all time on the ambulance or call center \\
\hline 3. & $\begin{array}{c}\text { Are they holding a GPS system for tracking their doctor or } \\
\text { ambulance location. }\end{array}$ \\
\hline 4. & Do they possess a patient tracking system \\
\hline 5. & Do they maintain a Patient/Doctor information system \\
\hline
\end{tabular}

Parameter-5 Patient/Doctor Information System: Two service providers partially are running IS while the other have no information system. The proposed model has an information system.

The information system of proposed model registers doctors and ambulance details as well as patient details. The information system allows all the registered doctors to update their availability status and GPS location coordinates through mobile app.

Patient/passenger dials the call center number through mobile app. This mobile app first sends the mobile GPS location coordinates to information system and connects the patient to call center agent.

The call center agent is capable to see the patient location and all available doctors and ambulance locations on the map by using information system. If the doctor thinks that the patient needs a doctor on the spot or needs to move hospital, then the agent redirects the nearest doctor or ambulance to the patient. The agent also sends the detail of the patient, such as GPS location and phone number to the doctor.

The located nearest doctor may be in the same train, or traveling in a train which is nearest to that train, traveling by road or any other place which is closer to the that train.

Fig. 9 clearly shows that the proposed ArchiMat service model satisfies all five parameters by yes green circle. That proves that the proposed model is better than others.

The five tests are performed to evaluate the proposed model using Google map. These tests are performed between the railway track of Karachi and Hyderabad as shown in Fig. 10. The results are shown in Table 2.

The results show that the proposed model successfully calculates the patient and doctor location through GPS

Mehran University Research Journal of Engineering \& Technology, Volume 36, No. 1, January, 2017 [p-ISSN: 0254-7821, e-ISSN: 2413-7219] 
system using mobile app. The calculated GPS coordinates are sent to the server in the form of latitude and longitude, where an application calculates the shortest distance between patient and doctor. The server side application enables the call center agent to trace all doctors and patient positions on map with distance as shown in Fig. 10.

Table 2 shows the five test results, and finding of these tests indicate that four times the doctor is nearer to the patient than the other rescue service stations and only one time a rescue service station is the nearest then the doctor from the patient.

\section{CONCLUSION}

In the first section, this research critically reviewed the top four EAF in conjunction with non-organization situation; and on the basis of this critical review, it is resolved that TOGAF/ArchiMat is an appropriate framework for creating new architecture in nonorganization situations. The second section of this research proposed the ArchiMate service layer model of m-Health using GPS system for train passengers. The critical analysis and discussion establishes that proposed ArchiMat service model is better than any other existing services for train passengers.

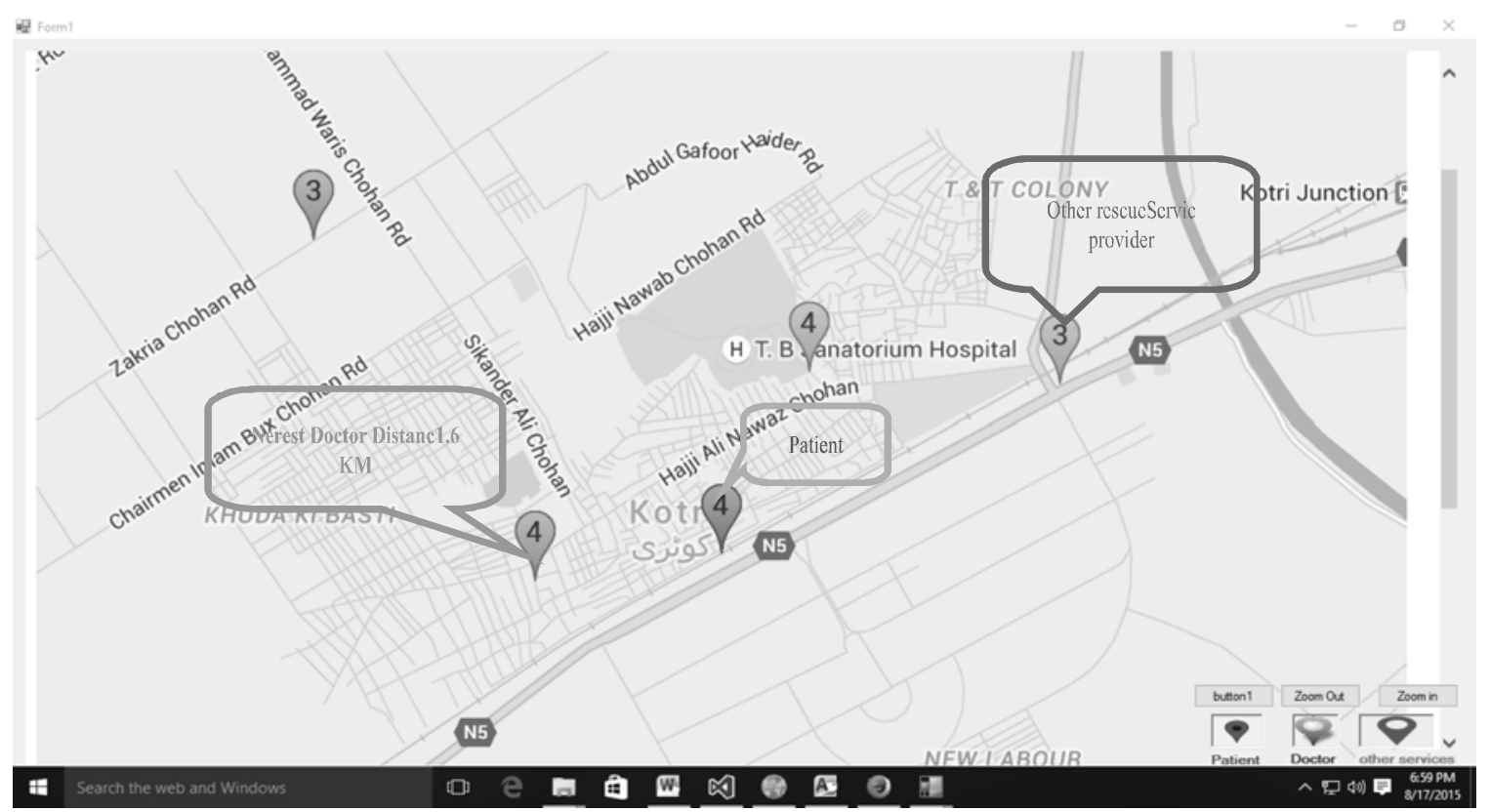

FIG. 10. DOCTORS, PATIENT AND OTHER EMERGENCY STATION ON GOOGLE MAP

TABLE 2. TEST RESULTS

\begin{tabular}{|c|c|c|c|c|}
\hline Test No & Location & $\begin{array}{c}\text { Dr. Distance from Patient } \\
(\mathrm{km})\end{array}$ & $\begin{array}{c}\text { Other Rescue Service Stations } \\
\text { Distance from the Patient } \\
(\mathrm{km})\end{array}$ & Nearest Object \\
\hline 1. & Kotri & 0.5 & 23 & \multirow{2}{*}{ Doctor } \\
\hline 2. & Jhampir & 14.5 & N/A & \\
\hline 3. & Station Meting & 8.0 & 3.5 & Other rescue service \\
\hline 4. & Ranpattahni & 1.5 & 4.7 & \multirow{2}{*}{ O. } \\
\hline 5. & Dabheji & 11.0 & & \\
\hline
\end{tabular}

Mehran University Research Journal of Engineering \& Technology, Volume 36, No. 1, January, 2017 [p-ISSN: 0254-7821, e-ISSN: 2413-7219] 


\section{ACKNOWLEDGEMENT}

All the relevant faculty members of the Department of Computer Science, Federal Urdu University of Arts, Science \& Technology, Karachi, Pakistan, have supported the work by positive opinion.

\section{REFERENCES}

[1] Ahsan, K., Shah, H., Kingston, P., "The Role of Enterprise Architecture in Healthcare-IT", 6 ${ }^{\text {th }}$ International Conference on Information Technology: New Generations, 2009.

[2] Zachman, J.A., "A Framework for Information Systems Architecture”, IBM System's Journal, Volume 26, No. 3, pp. 276, 1987.

[3] Suomi, R., et al., "Project E-Society: Building Bricks", 6th IFIP Conference on e-Commerce, e-Business and eGovernment, Springer, October 11-13, 2006, Turku, Finland, 2006

[4] Ahlemann, F., Stettiner, E., Messerschmidt, M., and Legner, C., "Strategic Enterprise Architecture Management: Challenges, Best Practices, and Future Developments", Springer, 2012.

[5] Tomkowicz, T., "Modeling as a Mechanism to Align Business Process Management with Enterprise Architecture: An Analysis from the Financial Services Industry", GRIN Verlag, 2007.

[6] Ross, J.W., Weill, P., and Robertson, D, "Enterprise Architecture as Strategy", Harvard Business Press, pp. 1-5, Boston, 2006.

[7] Urbaczewsk, L., and Mrdalj, S., "A Comparison of Enterprise Architecture Frameworks", Issues in Information Systems, Volume 7, No. 2, pp. 18-23, 2006.

[8] Zachman, J.A., "A Framework for Information Systems Architecture", IBM Systems Journal, Volume 26, No. 3, 1987.

[9] Marques, C., and Sousa, P., "A Method to Define an Enterprise Architecture using the Zachman Framework", ACM Symposium on Applied Computing, 2004.
[10] Sessions, R., “A Comparison of the Top Four EnterpriseArchitecture Methodologies", Microsoft, 2007. [Online]Available: https://msdn.microsoft.com/en-us/ library/bb466232.aspx.[Accessed June 2015]

[11] FEA Consolidated Reference Model Document Version 2.3, Office of Management and Budget, 2007. [Online] Available: URL: http://www.whitehouse.gov/sites/default/ files/omb/assets/fea_docs/FEA_CRM_v23_Final_ Oct 2007 Revised.pdf[Accessed June 2015].

Goethals, F., "An Overview of Enterprise Architecture Framework Deliverables", 2003 [Online] Available: www.econ.kuleuven.ac.be/leerstoel/sap/FramesPage.htm [Accessed June 2015]

[13] Gonçalo, A., Barateiro, J., Becker, C., Borbinha, J., and Vieira, R., "Modeling Contextual Concerns in Enterprise Architecture", 15th IEEE International Enterprise Distributed Object Computing Conference Workshops, DOI:10.1109/EDOCW, 2011

[14] Hanschke, S., Ernsting, J., and Kuchen. H., "Integrating Agile Software Development and Enterprise Architecture Management", 48th Hawaii International Conference on System Sciences, pp. 4099-4109, 2015.

[15] Atkinson, C., and Tunjic, C., "Towards Orthographic Viewpoints for Enterprise Architecture Modeling", IEEE 18th International Enterprise Distributed Object Computing Conference Workshops and Demonstrations, Computer Society, 2014.

[16] Lankhorst M., et. Al., "Enterprise Architecture At Work", Springer Verlag, Heidelberg, 2005

[17] Arpini, R.H., and Almeida, J.P.A., "On the Support for the Assignment of Active Structure and Behavior in Enterprise Modeling Approaches", Proceedings of 27th Annual ACM Symposium on Applied Computing, 2012.

[18] Ministry of Railways, "Principal Statistics", Government of Pakistan, 2014. [online] Available:http:// www.pakrail.com/ybbf.pdf [Accessedon 11 June 2015] 
[19] Asim, M., and Nafees Q.I., "Pakistan Railways at the Verge of Collapse: A Case Study", International Review of Management and Business Research, Volume 3, No. 3, 2014.

[20] Faq About The Pakistan Railways Passenger Service, "Is Medical Assistance Available On Trains?", [Online]Available]: http://www.pakrail.com/faaqqqq.htm [Accessed 11 June 2015]
[21] Annual Report 2013, Pakistan Telecommunication Authority [Online] Available:http://www.pta.gov.pk/ annual-reports/annreport2013_1.pdf [Assessed 12 June 2015].

[22] Pakistan Economic Survey 2013-2014, "Highlights of Pakistan Economic Survey 2013-14", [Online] Available: http://www.finance.gov.pk/survey/chapters_14/ Highlights_ES_201314.pdf[Assessed08Augst 2015]. 